\title{
Advancement of physical process by mental activation: A prospective controlled study
}

\author{
S. Lehrl, PhD; ${ }^{1}$ J. Gusinde, MD; $^{2}$ S. Schulz-Drost, MD; ${ }^{2}$ A. Rein, MD; ${ }^{1}$ P. M. Schlechtweg, MD, MHBA; ${ }^{3}$ \\ H. Jacob, MD; ${ }^{1}$ S. Krinner, MD; ${ }^{2}$ K. Gelse, MD; ${ }^{2}$ J. Pauser, MD, MHBA; ${ }^{2}$ Matthias H. Brem, MD, MHBA ${ }^{4^{*}}$ \\ Departments of ${ }^{1}$ Psychiatry, ${ }^{2}$ Surgery, Division of Traumasurgery, and ${ }^{3}$ Radiology, Friedrich-Alexander-Universität \\ Erlangen-Nuremberg, Erlangen, Germany; ${ }^{4}$ Departments of Traumatology and Orthopaedy, Klinikum Nuernberg, \\ Nuernberg, Germany
}

\begin{abstract}
According to the literature, patients who are significantly impaired by physical mobility limitations can be rehabilitated if the patient's working memory is used to capacity. The conclusion that periodic mental activity improves physical rehabilitation should be evaluated. This is a prospective, controlled, and randomized open study of patients who underwent a total hip arthroplasty (THA). Sixteen patients who played the video game Dr. Kawashima's Brain Training: How Old Is Your Brain? were compared in terms of rehabilitation progress to 16 individuals who did not play. Harris Hip and Merle d'Aubigné scores were evaluated $1 \mathrm{~d}$ preoperation and again $12+/-1 \mathrm{~d}$ postoperation. Preoperation, no significant differences in hip scores between the gaming and control groups were found (median Harris Hip score: 39 vs 33, respectively, $p=0.304$; median Merle D’Aubigné score: 12 vs 9 , respectively, $p=0.254$ ). Postoperation, there were significant differences between the gaming and control groups (median Harris Hip score: 76.0 vs 56.5, respectively, $p=0.001$; median Merle D’Aubigné score: 16.0 vs 13.5 , respectively, $p=0.014$ ). Within both groups, the posttest scores significantly improved; however, the increase for the gaming group was greater for both measures. Because the influence of age, sex, and level of education can be excluded, it can be assumed that mental activities can improve physical rehabilitation after THA.
\end{abstract}

Key words: Harris Hip Scale, hip score, hospitalization, mental activity, Merle D’Aubigné Scale, physical mobility, physical rehabilitation, telehealth, total hip arthroplasty, working memory.

\section{INTRODUCTION}

\section{Objectives}

A variety of surgical interventions limit the physical functionality of patients in the postoperative setting. The idea of enhancing rehabilitation using mental activation may be an important addition to physical rehabilitation procedures, especially if the mental activation procedures are inexpensive. If such mental activation is not a psychological burden to patients, it might even be entertaining and encourage patients to look forward to continuing such beneficial procedures without hesitation.

In addition to being potentially pleasant, mental activation therapy might also ameliorate health problems, establish new social contacts, or stabilize existing friendships by increasing the number of visits to rehabilitation sessions. These benefits may make treatment sessions more pleasant and less aversive.

\footnotetext{
Abbreviations: SD = standard deviation, THA = total hip arthroplasty.

*Address all correspondence to Matthias H. Brem, MD, MHBA; Klinikum Nuernberg, Breslauerstr 201, D-90471 Nuernberg, Germany.

Email: Matthias.Brem@klinikum-nuernberg.de http://dx.doi.org/10.1682/JRRD.2011.05.0086
} 


\section{Pain Amelioration by Mental Activation}

Observations of daily life and individual reports of, for example, seriously injured servicemembers have revealed that negative feelings such as pain and fear can be ameliorated by mental activation [1].

Experimental studies (overview in Eccleston [2]) have confirmed that the perception of pain can be reduced by performing mental exercises. Pain signaling distraction is not adequate, and moreover, "working memory" processes must work at full capacity of information load. Working memory, which is the center of cognitive information management, is classified as the basis of intellectual performance and is a capacity that is independent of experience. The ability to successfully integrate new information from the domains of school, work, and daily life in a knowledgebased society has been named "fluid intelligence" in the literature [3]. Increasingly, intelligence researchers (including Weiss, Miyake and Shah, and Colom et al. [4-6]) have replaced this concept with working memory because this term is more precise and brain-based.

Working memory is the product of two elementary components: "information processing speed" (bits per second) and "length of immediate memory" (seconds) often called "memory span," wherein each has a defined capacity [7]. As a result, the amplitude of information that can be consciously processed is narrowly restricted [7], and for the average adult, this information amplitude cannot exceed 80 bits.

Using this information, it can be deduced that if a mental activity uses the full capacity of working memory or its two components, there is no available space within the consciousness for the cognition of paresthesia and negative feelings such as fear. Cziske and Lehrl and Terkelsen et al. have published evidence for the validity of this model of working memory in terms of utilized capacity [8-9]. For example, Terkelsen et al. observed the level of pain perception in subjects decrease when patients had to solve arithmetic problems in a short, predetermined amount of time [9]. On the other hand, no decreases in pain perception were observed for patients who concentrated on the location of the pain, which is an activity that does not occupy the working memory or its components.

\section{Better Mobility as Result of Mental Activation?}

Most likely, mental activities that reduce pain perception block specific body movements that cause pain, resulting in an increased mobility; however, distracting mental activities inhibit conscious physical exercises. In this setting, patients can only perform automatic body movements that began before the onset of the mental activity; however, this type of rehabilitation process is uncommon for physiotherapy.

Many mental activities are connected to head or hand movements (e.g., reading, talking, writing), and it may be that these movements also occur in combination with latent simultaneous movements of lateral body parts, which also constitute exercise. In practice, simultaneous movements of lower limbs have no effect on rehabilitation.

In contrast, mental activation appears to have a larger influence on rehabilitation. Therein, one has to distinguish between (1) immediate physical activity following mentally increased excitability, (2) its increase by frequent exercise, and (3) learned effects in regard to content.

1. Mental excitability is maintained for several minutes after exercise. During this short period, a patient's participation in physical exercises, as required in physical therapy, is increased. This beneficial situation is only given when a patient immediately switches from mental activation to physical exercise.

2. A more influential factor with respect to physical exercise might be that people with a high level of daily mental activity, compared with less busy people, become increasingly more mentally effective during subsequent days, and therefore, become more interested and excitable [10-14]. People who participate in significant mental exercise participate more willingly and with more concentration in physical therapy. Consequently, they improve faster.

3. Simple learning theory should be kept in mind: people with mental activation who are in physical pain are distracted. They do not notice corporal pain, and therefore, they do not save it in their declarative memory. As soon as they move, they become less inhibited by memories of corporal pain.

Despite the practical relevance and plausibility of the assumption that mental activation after surgical procedures assists in the rehabilitation of corporal mobility, there are no appropriate studies in the literature. Schimmelpfennig described 145 adult inpatients who underwent mental activation training after orthopedic or phlebological procedures [15]. These patients became more open-minded and communicative, showed a greater motivation in anastasis, were more swiftly able to coordinate their movements (e.g., by learning to walk with forearm crutches), and needed less time for recovery. Schimmelpfennig does not present the detailed statistics and measurement procedures 
that led to the study conclusions [15]. Furthermore, the study had no control group. Because conclusive scientific evidence of these results is still missing, more research in this field is necessary.

Because of inadequate scientific evidence, this study aims to answer whether mental activation and activities that use working memory support the postoperative rehabilitation of surgical patients who have limited mobility.

\section{METHODS}

\section{Patients and Experimental Design}

This investigation consisted of a prospective, nonblinded, controlled, and randomized study that included inpatients after total hip arthroplasty (THA). For all of the included patients, we chose the same aditus (posterolateral) and a prosthesis from the same manufacturer. The surgical procedure was the same for all patients and proceeded in a standardized way. All the surgeons were trained in the same way, and the procedure was performed according to those standards. The duration of the procedure was $53.50 \pm$ 25.59 min (mean \pm standard deviation [SD]) for the gaming group and $68.40 \pm 22.02 \mathrm{~min}$ for the control group. Inclusion criteria consisted of patients of both sexes, aged $\geq 45$ years, and with legal competence. For analgesia, medication with a strong modulating influence on mental capacity had to be avoided. Postoperation, all of the patients received the same regimen of pain relief medications.

In this study, 16 patients played a video game consisting of tasks that challenged either the information processing speed or the memory span for at least $30 \mathrm{~min} / \mathrm{d}$ (gaming group). The control group did not play the game at all.

\section{Game}

Dr. Kawashima's Brain Training: How Old Is Your Brain? (Nintendo; Kyoto, Japan) appeared to be an appropriate choice for this study [16]. This video game includes several types of tasks that must be solved as quickly and as correctly as possible. Comparisons with usual tests for the individual speed of information processing and memory span showed that the majority of the tasks were designed to push the individual's speed of mental data processing $[4,6,10]$. The remaining tasks challenged the memory span or the two components of working memory together. For example, patients had to add or subtract numbers quickly, tap numbers shown for preoperation and again at discharge (12 $\pm 1 \mathrm{~d}$ postopera- a second in increasing order, or keep track of the number of people who entered and left a house.

\section{Research Variables and Test Intervals}

We used sex, age, and crystallized intelligence as demographic attributes when selecting patients to be included in this study; hence, the knowledge repository had to be evaluated via a 20-item multiple choice vocabulary test [17]. Brem et al. details other medical and psychometric variables [18].

We noted the Harris Hip and Merle d'Aubigné scores at admission (generally noted $1 \mathrm{~d}$ preoperation) and on the day of discharge (12 $\pm 1 \mathrm{~d}$ after admission) [19-20]. After the first examination, we explained the game to the gaming group and they played for the first time. Starting on day 2 postoperation, the gaming group started to play for at least $30 \mathrm{~min} / \mathrm{d}$ under the supervision of a study nurse who was present throughout.

\section{Specific Assumptions}

The given video game tasks should be solved quickly and correctly and should use all of the working memory capacity. As previously mentioned, we expected the gaming group to have higher Harris Hip and Merle d'Aubigné scores at discharge than the control group.

\section{Statistical Procedures}

Because of the type of data characteristics (no metric level and no Gaussian distribution), we performed nonparametric statistics for the statistical analyses. Upon the demonstration of location and dispersion parameters, we added the arithmetic average and SD, which is consistent with most other publications.

\section{RESULTS}

Although age $\geq 45$ years was a criterion for inclusion, we included a 44-year-old patient in the control group because he missed this criterion by just a few months. In both samples, 6 of the 16 patients (37.5\%) were male. The sex and age distributions of both groups (Table 1) were similar. Notably, the gaming group had a significantly higher level of general knowledge (Table 1). As a result, we needed to control for this factor in order to minimize its influence on the hip score results. The hip scores of these two patient groups were evaluated 1 day tion, $p=0.984$, 2-sided). 
JRRD, Volume 49, Number 8, 2012

Table 1.

Patient demographics.

\begin{tabular}{|c|c|c|c|c|c|c|}
\hline Variable & No. in Group & Median & Mean \pm SD & Minimum & Maximum & Probability $^{*}$ \\
\hline Age (yr) & & & & & & $0.522^{\dagger}$ \\
\hline Control & 16 & 66.0 & $68.9 \pm 13.9$ & 44 & 86 & \\
\hline Crystallized Intelligence (IQ) & & & & & & $0.016^{\dagger}$ \\
\hline Control & 16 & 107.0 & $106.4 \pm 14.7$ & 85 & 136 & \\
\hline \multicolumn{7}{|l|}{ Harris Hip (score) } \\
\hline Preoperation & & & & & & $0.304^{\dagger}$ \\
\hline Control & 16 & 33.0 & $32.9 \pm 9.9$ & 20 & 50 & \\
\hline Gaming & 14 & 39.0 & $38.9 \pm 14.3$ & 19 & 69 & \\
\hline Postoperation & & & & & & $0.001^{\ddagger}$ \\
\hline Control & 15 & -27.5 & $-28.6 \pm 12.4$ & -50 & -11 & \\
\hline Gaming & 14 & -42.5 & $-37.6 \pm 14.0$ & -62 & -13 & \\
\hline \multicolumn{7}{|l|}{ Merle d’Aubigné (score) } \\
\hline Preoperation & & & & & & $0.254^{\dagger}$ \\
\hline Control & 16 & 9.0 & $9.9 \pm 3.8$ & 5 & 18 & \\
\hline Gaming & 14 & 12.0 & $11.1 \pm 3.4$ & 5 & 17 & \\
\hline Postoperation & & & & & & $0.014^{\ddagger}$ \\
\hline Control & 15 & 13.5 & $13.4 \pm 3.1$ & 9 & 18 & \\
\hline Gaming & 15 & 16.0 & $15.8 \pm 1.8$ & 13 & 18 & \\
\hline
\end{tabular}

\section{Characteristics of Hip Scores}

The Harris Hip scores did not statistically distinguish the preoperative inference, yielding values of 33 and 39 (control and gaming group medians, respectively) (Table 1). These scores increased in both groups for all patients. The control group reached a middle range score, whereas the gaming group, with a median of 76 , reached a higher range score. The hip scores significantly differed $(p=0.001$; Table 1) to the advantage of the gaming group. In terms of pre- and posttest hip scores, the gaming group showed a significantly larger increase in posttest hip scores ( $p=$ 0.041; Table 1).
The hip score results were approximately the same for the Merle d'Aubigné score; however, the observed difference between the increases of the gaming and control groups was not significantly different (Table 1).

\section{Coherence in Age, Sex, and Intelligence Quotient}

Because the literature uses both the Pearson $(r)$ and Spearman rank correlations, we used both. Their results agree with the shown results. We found no correlations between the demographic characteristics of age and sex and the scores on both hip measures (Table 2). The level of crystallized intelligence, which is a concept that reflects 
Table 2.

Pearson (cursive, lower triangle matrix) and rank correlations (Spearman) between demographic attributes and hip parameters $(r$ and rho $=r \times 100$, respectively).

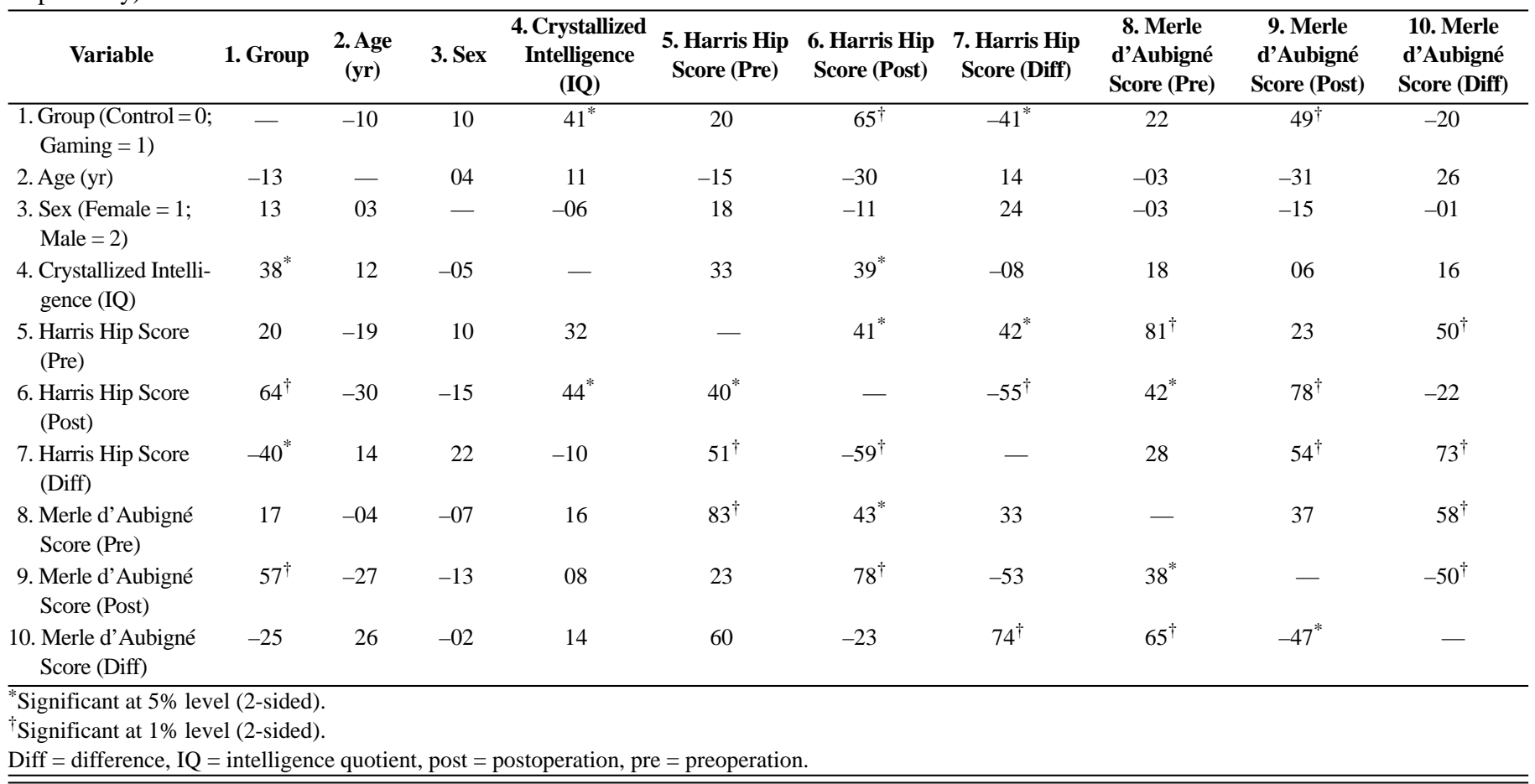

general knowledge and education, correlated with neither preoperative hip scores nor with changes in progress.

\section{DISCUSSION}

According to the hip measures, the gaming and control groups both performed at average levels for both measures. According to the postoperative measurements, both samples exhibited statistically significant increases in hip score. Although the values of both groups did not appreciably differ preoperation, we saw a significant difference postoperation favoring the gaming group. The control group performed in the upper-middle range, whereas the mentally activated patients performed in the lower edge of the upper quartile of valuation.

Within the samples, we observed, as expected, a larger hip score increase in the gaming group; however, only the difference in the Harris Hip score was statistically significant. This lack of significance could be explained by methodological issues. It is possible that the values of the Merle d'Aubigné score (0-18 points) are not as informative as the Harris Hip score (0-100 points) because this score was at a higher level before the surgical procedure (at least half of the maximum), whereas the Harris Hip score was $<40$ percent and reached values that were closer to the maximum postoperation (ceiling effect). Several patients reached maximum scores on the Merle d'Aubigné scale but did not receive maximum scores on the Harris Hip scale.

The results are significant for the Harris Hip scale, which is a very detailed score for the outcome measurement of hip diseases and treatment options. A difference of 16 points shows a much better clinical outcome and functional outcome with a better mobility of the hip treatment. The Merle d'Aubigné score is a less detailed score. The difference of 2.4 points is not statistically significant, but the clinical outcome is also better concerning functional evaluation and mobility of the patient.

Because of the Harris Hip results, we assume that the results in the gaming group are appropriate. Nevertheless, the main question remains whether the observed increase in hip score is a direct result of the gaming or whether other variables are potentially responsible. Age and sex cannot explain these differences because we found no differences in both groups with respect to these variables at the start of the study. Furthermore, these two 
demographic data points do not correlate with the score differences (Table 2).

In contrast, the gaming group participants showed a significantly higher level of crystallized intelligence. The intelligence quotient correlates with education, social class, physical mobility, the global state of health, and even lifespan [21]. Because of these correlations, this quotient could influence the results of both hip measures. As shown by the correlation of intelligence quotient with the initial hip scores and by the difference in hip score scales (Table 2), we had undetectable correlations.

Our expectation was that the gaming group has higher scores. This might influence the outcome because the study could not be fully blinded. We achieved protection against this experimenter effect because the persons mainly responsible for this research were not immediately involved in the administration of the psychometric tests and supervision of the gaming group. These activities were delegated to four persons performing evaluations independent from the physiotherapy staff. In total, the specific activities of this study were executed by approximately a dozen people who performed their routine jobs and partially did not know each other. We believe that this was a good protection against a bias caused by the planning researchers.

Thus, we think that our expectations have been fulfilled, i.e., increased amounts of mental exercise lead to a faster rehabilitation of hip function. In comparison with the control group, the differences in the results are probably even greater because the hip measures, especially performance measures, are themselves types of mental training. The control group had to pass these performances measures twice postoperation.

How can the results of this study be explained? It can be assumed that the full capacity of each patient's working memory is used when playing Dr. Kawashima's Brain Training: How Old Is Your Brain? because of the distracting components of the game. The working memory capacity of the gaming group significantly increased throughout the test in contrast with the control group [18]. We saw a positive correlation between increased mental performance and changes in hip scores ( $\mathrm{d}=$ difference) for all patients $(n=32)$; however, we reached statistical significance for only one of the scoring scales $\left(r_{\mathrm{d}}\right.$ capacity of working memory according to Harris Hip score: 0.16, $p=$ $0.204 ; r_{\mathrm{d}}$ capacity of working memory according to Merle d'Aubigné score: 0.41, $p=0.015$; 1-sided each). As an estimation for the upper limit, the correlation in the changes of both hip scores can be used: $r=0.74$; however, the same examiner collected the data for both scores within a short interval. In contrast, different people collected the measurements of working memory capacity 4 days earlier. According to these terms, we suppose that mental activation by way of increased mental efficiency can be associated with the observed improved physical rehabilitation outcomes. With the available data, we cannot fully determine which of the following this finding comes from: an increased willingness to participate in physical therapy, improved stamina, a more differentiated coordination of motion, a more significant decrease in pain perception, or improved motion in the entire body during the mental activation process.

We also cannot exclude the possibility, as suggested by learning theory, that the gaming group had less time for the perception of their own body than the control group. We cannot rule out that these participants had less time to perceive pain because of their movements and their need to maintain their somatic position longer. As of yet, we have no data to evaluate these questions. Another limitation of this study is the relatively small number of patients; further study is needed.

\section{CONCLUSIONS}

Games such as Dr. Kawashima's Brain Training: How Old Is Your Brain?, a video game that uses the full capacity of the mental working memory, might be a useful tool for patients after a short introduction as untapped resources that support the rehabilitation of physical mobility. The advantages of playing may be even greater than were shown in this study because, for statistical reasons, the control group had to participate in other types of mental performance tests, which are also mentally activating tests.

One important factor, though probably not the only one, related to the effect of mental activation on physical mobility is the observed increase in mental fitness, which may lead to a greater willingness and stamina for physical exercises. There may be other important effects of this activation that were not demonstrated by this study. For these reasons, additional studies in this field are necessary.

\section{ACKNOWLEDGMENTS}

Author Contributions:

S. Lehrl and J. Gusinde contributed equally to this article. 
Study concept and design: S. Lehrl, M. H. Brem.

Acqusition of data: S. Gusinde, S. Schulze-Drost, A. Rein, P. M. Schlechtweg, H. Jacob, S. Krinner, K. Gelse.

Analysis and interpretation of data: S. Lehrl.

Drafting of manuscript: S. Lehrl, S. Gusinde, P. M. Schlechtweg,

J. Pauser, M. H. Brem.

Critical revision of manuscript for important intellectual content:

S. Lehrl, S. Gusinde, J. Pauser, M. H. Brem.

Statistical analysis: S. Lehrl.

Administrative, technical, or material support: S. Gusinde.

Obtained funding: S. Lehrl, M. H. Brem.

Study supervision: S. Gusinde, M. H. Brem.

Financial Disclosures: The authors have declared that no competing interests exist.

Funding/Support: This material is based on work supported by Euro RSCG ABC, including funding for scientific presentations by Euro RSCG ABC at international conferences. The funding institution did not have any influence on the study design, study execution, analysis and interpretation of data, or writing of the manuscript.

Additional Contributions: We would like to thank Ms. S. Massute for her assistance with this article.

Institutional Review: Informed consent was obtained from each patient. The study was approved by the local ethics committee and conformed to the principles of the Declaration of Helsinki.

Participant Follow-Up: The authors do not plan to inform participants of the publication of this study. However, participants have been encouraged to check the Web site of Dr. Brem for updated publications.

\section{REFERENCES}

1. Beecher HK. The measurement of subjective responses; quantitative effects of drugs. New York (NY): Oxford University Press; 1959.

2. Eccleston C. The attentional control of pain: methodological and theoretical concerns. Pain. 1995;63(1):3-10.

[PMID:8577487] http://dx.doi.org/10.1016/0304-3959(95)00093-8

3. Cattell R. Some theoretical issues in adult intelligence testing. Psychol Bull. 1941;38:592.

4. Weiss V. Die IQ-Falle: Intelligenz, sozialstruktur und politik. Graz (Austria): Leopold Stocker Verlag; 2000. German.

5. Miyake A, Shah P, editors. Models of working memory: mechanisms of active maintenance and executive control. Cambridge (MA): Cambridge University Press; 1999.

6. Colom R, Rebolloa I, Palaciosa A, Juan-Espinosa M, Kyllonen PC. Working memory is (almost) perfectly predicted by g. Intelligence. 2004;32(3):277-96.

http://dx.doi.org/10.1016/j.intell.2003.12.002

7. Frank H. Über grundlegende Sätze der Informationspsychologie. Grundlagenstud Kybern Geisteswissenschaften. 1960;1:25-32. German.

8. Cziske R, Lehrl S, editors. Magnitude of pain and anxiety depending on limited capacity of consciousness. Proceed- ings of the International Congress on Cybernetics; 1980; Namur, Belgium.

9. Terkelsen AJ, Andersen OK, Mølgaard H, Hansen J, Jensen TS. Mental stress inhibits pain perception and heart rate variability but not a nociceptive withdrawal reflex. Acta Physiol Scand. 2004;180(4):405-14. [PMID:15030382] http://dx.doi.org/10.1111/j.1365-201X.2004.01263.x

10. Weidenhammer W, Glowacki H, Grässel E. Wie führt man zerebrales Training durch-was hat sich bewährt? Pregeriat Geriat Rehabil. 1986;2:66-76. German.

11. Klingberg T, Fernell E, Olesen PJ, Johnson M, Gustafsson P, Dahlström K, Gillberg CG, Forssberg H, Westerberg H. Computerized training of working memory in children with ADHD — a randomized, controlled trial. J Am Acad Child Adolesc Psychiatry. 2005;44(2):177-86. [PMID:15689731] http://dx.doi.org/10.1097/00004583-200502000-00010

12. Rueda MR, Rothbart MK, McCandliss BD, Saccomanno L, Posner MI. Training, maturation, and genetic influences on the development of executive attention. Proc Natl Acad Sci U S A. 2005;102(41):14931-36. [PMID:16192352] http://dx.doi.org/10.1073/pnas.0506897102

13. Willis SL, Tennstedt SL, Marsiske M, Ball K, Elias J, Koepke KM, Morris JN, Rebok GW, Unverzagt FW, Stoddard AM, Wright E; ACTIVE Study Group. Long-term effects of cognitive training on everyday functional outcomes in older adults. JAMA. 2006;296(23):2805-14.

[PMID:17179457] http://dx.doi.org/10.1001/jama.296.23.2805

14. Jaeggi SM, Buschkuehl M, Jonides J, Perrig WJ. Improving fluid intelligence with training on working memory. Proc Natl Acad Sci U S A. 2008;105(19):6829-33. [PMID:18443283] http://dx.doi.org/10.1073/pnas.0801268105

15. Schimmelpfennig L. Ohne Kopf geht's nicht. Geistig Fit. 2000;10(2):6-9. German.

16. Kawashima R. Train your brain more: 60 days to an even better brain. London (England): Penguin; 2008.

17. Lehrl S, Triebig G, Fischer B. Multiple choice vocabulary test MWT as a valid and short test to estimate premorbid intelligence. Acta Neurol Scand. 1995;91(5):335-45.

[PMID:7639062]

http://dx.doi.org/10.1111/j.1600-0404.1995.tb07018.x

18. Brem MH, Lehrl S, Rein AK, Massute S, Schulz-Drost S, Gelse K, Schlechtweg PM, Hennig FF, Olk A, Jacob HJ, Gusinde J. Stop of loss of cognitive performance during rehabilitation after total hip arthroplasty-prospective controlled study. J Rehabil Res Dev. 2010;47(9):891-98.

[PMID:21174253] http://dx.doi.org/10.1682/JRRD.2010.01.0011

19. Harris WH. Traumatic arthritis of the hip after dislocation and acetabular fractures: treatment by mold arthroplasty. An 
JRRD, Volume 49, Number 8, 2012

end-result study using a new method of result evaluation. J Bone Joint Surg Am. 1969;51(4):737-55. [PMID:5783851]

20. D’Aubigné RM, Postel M. The classic: functional results of hip arthroplasty with acrylic prosthesis. 1954. Clin Orthop Relat Res. 2009;467(1):7-27. [PMID:18941852] http://dx.doi.org/10.1007/s11999-008-0572-1

21. Gottfredson LS. Foreword to "Intelligence and Social Policy”. Intelligence. 1997;24(1):1-12. http://dx.doi.org/10.1016/S0160-2896(97)90010-6

Submitted for publication May 12, 2011. Accepted in revised form January 17, 2012.
This article and any supplementary material should be cited as follows:

Lehrl S, Gusinde J, Schulz-Drost S, Rein A, Schlechtweg PM, Jacob H, Krinner S, Gelse K, Pauser J, Brem MH. Advancement of physical process by mental activation: A prospective controlled study. J Rehabil Res Dev. 2012; 49(8):1221-28.

http://dx.doi.org/10.1682/JRRD.2011.05.0086

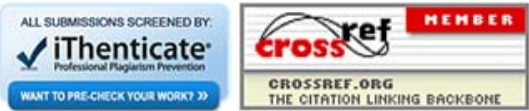

